\title{
Decreasing of the level of ecological pollution at processing of chloral-organic wastes of the production of 1,2-dychloro ethane
}

\author{
Mykola Shpariy $^{1}$, Volodymyr Starchevskyy ${ }^{2}$
}

1. LTD «KARPATNAFTOCHIM», Kalush, UKRAINE, E-mail: shparijmv@gmail.com

2. Department of physical, analytical and general chemistry, Lviv Polytechnic National University,

UKRAINE, E-mail: vstarchevskyy@gmail.com

\begin{abstract}
Ukrainian industry is adopting of the modern environmental standards of production. One of the most promising ways of reaching of those aims is improvement of existing technological schemes by use of new catalytic systems.
\end{abstract}

Keywords: catalytic system, environmental standards

At the production of 1,2-dychloro ethane by direct chlorination of ethylene amount of obtained DCE is $98,2-99,4 \%$, and as by-products are created created vinyl chloride, four chloro carbon, 3-chloro ethane, 3-chloro ethylene and others, that after rectification are transferred to the burning stage. During this stage are created products such as chloral hydrogen, that requires additional purification of the burned gases from harmful additives.

During use of sodium salt of perfluorosulfonic acid, as modifier for catalytic system, ammount of 3-chloral ethane decreases from $0.46 \%$ to $0.30 \%$ or in 1.53 times, and this dependence is directly proportional to the increase of sodium amount in catalytic solution (Fig.1).

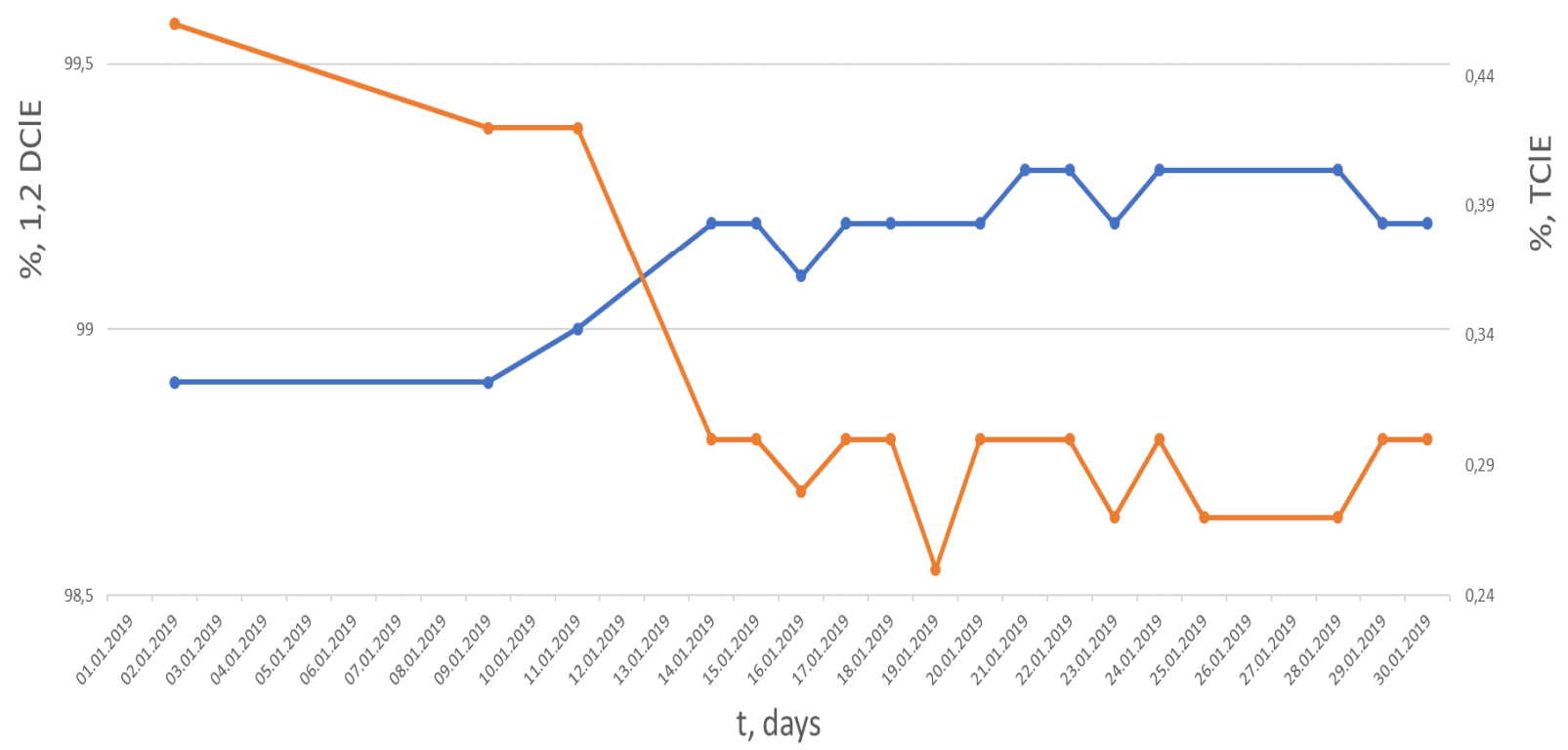

Fig. 1. The dependence of the yield 1,2 dichloro ethane (blue line) and trichloroethane (orange line) on time.

This way adding of catalytic complex modifier decreases amount of created by-products and therefore negative influence on environment. 